J. Lake Sci. (湖泊科学), 2013, 25(3):366-372

http: //www.jlakes.org. E-mail : jlakes@niglas.ac.cn

(C) 2013 by Journal of Lake Sciences

\title{
崇明岛“闸控型”河网水体富营养化特征及其影响因素”
}

张颖纯 ${ }^{1}$, 姜德刚 ${ }^{2}$, 李建华 ${ }^{1 * *}$

(1: 同济大学环境科学与工程学院长江水环境教育部重点实验室, 上海 200092)

(2:国家海洋局第三海洋研究所,厦门 361005 )

摘 要: 为研究崇明岛 “闸控型”河网水体富营养化特征及其与环境因子的相互作用, 以 2010 年各季节崇明岛河网水质 数据为基础, 探讨了环境因子与藻类的变化规律及其相互作用机制. 结果表明: 崇明岛河网水环境中营养盐水平较高, 氮 污染尤为严重. 长江引水进人岛内河网水环境后, 营养盐 ( 除 $\mathrm{SiO}_{3}-\mathrm{Si}$ )、Chl. a 含量和营养状态都出现了明显的升高. 与长 江引水相比, 河网内藻类群落 Chl. a 贡献比例的变化主要表现为硅藻比例的下降以及蓝藻和绿藻比例的上升. 尽管水温、 $\mathrm{pH}$ 、浊度以及营养盐中的 $\mathrm{TN} 、 \mathrm{TP} 、 \mathrm{NO}_{3}^{-}-\mathrm{N} 、 \mathrm{DOC}$ 的变化均与 Chl. a 含量显著相关, 但藻类群落对环境因子的响应关系存在 较大差异. 蓝藻的增加主要与水温和 $\mathrm{TP}$ 含量的升高有关; 绿藻与 $\mathrm{TN} 、 \mathrm{NO}_{3}^{-}-\mathrm{N}$ 的关系最为密切; 硅藻的变化只与浊度存在 明显正相关,营养盐并不是硅藻生长的促进因子.

关键词: 崇明岛;河网;富营养化;营养状态;环境因子

\section{Characteristics of eutrophication and its affecting factors in gate-controlled river network system of Chongming Island}

\section{ZHANG Yingchun ${ }^{1}$, JIANG Degang ${ }^{2} \&$ LI Jianhua ${ }^{1}$}

(1: Key Laboratory of Yangtze River Water Environment of Ministry of Education, College of Environmental Science and Engineering, Tongji University, Shanghai 200092, P. R. China)

(2: Third Institute of Oceanography, State Oceanic Administration, Xiamen 361005, P. R. China)

Abstract: In order to understand eutrophication and its relationships with environmental factors in gate-controlled river network system of Chongming Island, variations of environmental factors and algae as well as their interaction mechanisms were studied based on seasonal water quality data of the river network. Results indicated that the concentrations of nutrients in the river network were high and nitrogen pollution was particularly serious. The contents of nutrients, Chl. a and trophic state increased significantly after the Yangtze River water entered into the river network. The proportion of diatom decreased with increasing proportions of cyanobacteria and chlorophyta in the river network comparing with the water of the Yangtze River. Although water temperature, $\mathrm{pH}$, turbidity, TN, TP, $\mathrm{NO}_{3}^{-}-\mathrm{N}$ and DOC had significant correlations with algal biomass, the relationships between algal community and environmental factors were different. Water temperature and TP were the main factors of promoting growth of cyanobacteria; chlorophyta was closely related to $\mathrm{TN}$ and $\mathrm{NO}_{3}^{-}-\mathrm{N}$; and diatom was only related to the turbidity while nutrients were not promoting factors of diatom.

Keywords: Chongming Island; river network ; eutrophication; trophic state; environmental factors

水体富营养化问题是 21 世纪全球环境可持续发展面临的巨大挑战之一. 我国是水体富营养化的重灾 区, 特别是工业经济发达和人口密集地区周边水体的富营养化已严重影响了人们的生产和生活, 成为制约 区域社会经济发展的瓶颈 ${ }^{[1]}$. 水体富营养化最直观的表现为藻类数量的增多和种类的变化 ${ }^{[2]}$, 而藻类分布 和演替是由藻类本身的生理特点以及营养盐、光照、温度、水文条件等多种环境因子的变化和驱动引起

* 国家自然科学基金项目(41071301) 和上海市科委国际合作项目 (11230705600) 联合资助. $2012-05-23$ 收稿; 2013-01-13 收修改稿. 张颖纯,女,1990 年生,本科生; E-mail: yingchun1029@ sina. com.

** 通信作者; E-mail: leejianhua@ tongji. edu.cn. 
的 $^{[3-4]}$. 结合水域特征分析各环境因子与藻类的相互作用机制对于掌握水体富营养化进程至关重要.

崇明岛位于长江河口, 三面环江,一面临海, 是我国第三大岛, 也是上海市最具潜在战略意义的发展空 间之一. 岛内河网水资源主要由人为控制取自长江南支, 水质状况同时受长江和海水的影响 ${ }^{[5]}$. 近年来, 长 江口生活污水、城镇废水和农业面源污染的逐年加剧致使人河污染源不断增大. 此外, 崇明岛地势平坦且河 道引排基本受涵闸控制. 引排期河网在潮汐作用下通过开启南沿各水闸将长江水引人;而非引排期,各水闸 基本处于关闭状态, 将内河水体与长江隔离,形成了近乎封闭的水体. 非引排期间,这种 “闸控型” 的河道特 征直接导致了岛内河道水动力严重不足, 市县级河道水体流速变化范围仅为 $0.1 \sim 0.2 \mathrm{~m} / \mathrm{s}$. 受长江引水和 人为调控的双重作用,较高的营养盐水平和 “闸控型” 的河网特征势必增加崇明岛内河水体发生富营养化的 可能性. 但目前对于崇明岛河道水体的富营养化特征及其影响因素的研究较为匮乏. 因此本文以崇明岛河 网为研究对象, 对水质参数以及藻类群落特征开展全年季节性调查, 探讨不同季节下崇明岛河网藻类与环 境因子间的耦合关系, 为岛内河道富营养化防治和治理提供理论支持与决策依据.

\section{1 材料和方法}

\section{1 研究区域介绍}

崇明岛属沿海平原感潮河网地区,水资源主要来自长江水的供给和自然降雨形成的地表径流. 其中长 江引水主要由涵闸控制,多年平均可引水量为 $30.15 \times 10^{8} \mathrm{~m}^{3}$, 占岛内地表水资源总量的 $89.23 \%$; 而本地径 流仅占 $10.77 \%{ }^{[6]}$. 岛内河网密集, 全岛水域面积 $109.42 \mathrm{~km}^{2}$, 占岛域总面积的 $9.0 \%$. 全岛现有市县级骨干 河道 33 条, 总长 $390.22 \mathrm{~km}$, 是岛内规模最大、标准最高的河道, 也是主要的引排水河道. 各市县级河道河面 平均控制水位为 $2.6 \sim 3.0 \mathrm{~m}$, 是由崇明水务部门结合岛内生活、生产、生态用水以及调水安全等因素研究确 定的. 在崇明岛目前的水资源调度方式下, 全年岛内河网水体的水力停留时间超过 $15 \mathrm{~d}$.

\section{2 样品的采集与分析}

于 2010 年 1 月 (冬季)、 4 月 (春季)、7 月 (夏 季)、10月 (秋季) 对全岛域内 $\left(31^{\circ} 27^{\prime} 00^{\prime \prime} \sim\right.$ $\left.31^{\circ} 51^{\prime} 15^{\prime \prime} \mathrm{N}, 121^{\circ} 09^{\prime} 30^{\prime \prime} \sim 121^{\circ} 54^{\prime} 00^{\prime \prime} \mathrm{E}\right) 2$ 条市级河 道 (南横引河、北横引河) 和 6 条县级河道 (新建港、 鸽笼港、老滧港、新河港、堡镇港、八滧港) 以及崇西 水闸 (作为长江引水背景值) 共计 59 个监测点开展 表层水样 (河面水位下 $0.5 \mathrm{~m}$ 处) 的采集与现场监 测 ( 图 1).

现场监测中,采用美国哈希 (HQ40d) 便携式多 参数水质分析仪测定 $\mathrm{pH}$ 、溶解氧 ( DO) 、水温和电 导率; 采用散射光浊度仪 (WGZ-1A) 测定水体浊度. 水质指标中溶解性有机碳 (DOC) 的含量用有机碳分

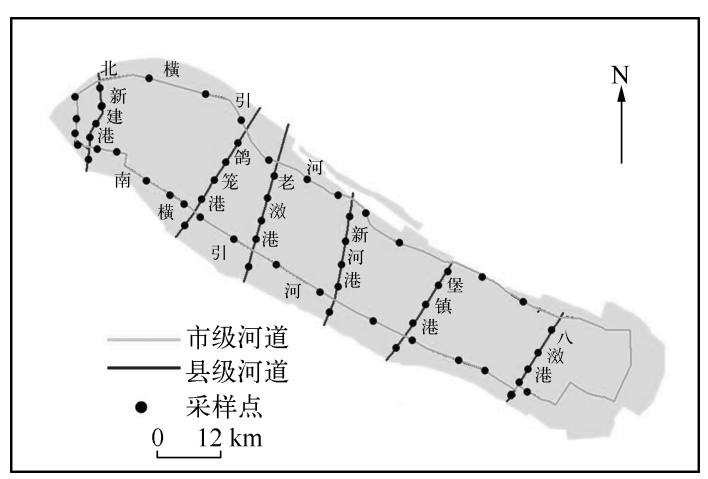

图 1 崇明岛采样点分布 析仪 ( TOC Vcph,Shimadzu) 测定. 氨氮 $\left(\mathrm{NH}_{3}-\mathrm{N}\right)$ 、硝

态氮 $\left(\mathrm{NO}_{3}^{-}-\mathrm{N}\right)$ 、总氮 $(\mathrm{TN})$ 、总磷 $(\mathrm{TP})$ 、可溶性硅酸盐 $\left(\mathrm{SiO}_{3}-\mathrm{Si}\right)$ 的含量均采用连续流动化学分析仪 ( QuAAtro, Bran Luebbe) 测定. 其中氨氮的测定采用水杨酸法, 显色波长为 $660 \mathrm{~nm}$; 硝态氮和总氮首先经过镉 柱还原为亚硝酸盐, 而后采用 N-1-萗-乙二胺一偶氮法测定, 显色波长为 $550 \mathrm{~nm}$; 总磷的测定采用磷钼蓝比色 法, 显色波长 $880 \mathrm{~nm}$; 硅酸盐的测定采用硅锄蓝比色法, 显色波长 $820 \mathrm{~nm}$. 使用浮游植物菼光仪(Phyto-PAM, Walz) 通过活体藻细胞叶绿素苂光来测定水体中 Chl. a 含量. 在 Meas. Freq. 为 32 的条件下测量微藻苂光 Chl. a 含量, 并通过传统方法 (热乙醇法) ${ }^{[7]}$ 进行校正.

\section{3 数据处理与分析}

相关性分析和同时圥余度分析 (Redundancy Analysis,RDA) 分别在 SPSS 13.0 和 CANOCO 4.5 软件中进 行. RDA 是一种直接用于描述两个矩阵之间关系的渐变分析方法 ${ }^{[8]}$, 同时也是分析藻类组成与环境因子之 间对应关系的有效工具. 在环境因子特征变量构成的空间内, 对环境变量和藻种进行排序作图, 可以直观地 
反映出藻类与环境因子之间的对应关系. 为使藻类生物量和环境因子的数据获得正态分布, 将其进行 $\lg (x+1)$ 转换. 在 2 个主轴构成的平面中, 箭头表征了环境因子在平面上的相对位置, 向量长短代表其在主 轴中的作用,箭头所处象限表示环境因子与排序轴之间的正负相关性.

\section{2 结果与讨论}

\section{1 水环境因子的季节变化规律}

崇明岛河网水体呈中性偏弱碱性且有氧状态占主导地位. 各季节河道中水体浊度均值在 43. 1 57.0 NTU之间, 均低于相应季节长江引水的浊度 (表 1). 这主要是因为长江引水在进人岛内后, 水动 力下降引起泥沙沉降的同时, 导致了浊度的降低. 从电导率的季节变化看, 冬、春季节河网的电导率明显高 于夏、秋季节 (表 1). 枯水期东海涨潮流的人侵是造成冬春季河道水体电导率偏高的主要原因.

表 1 崇明岛河网和长江引水中环境因子和 Chl. a 的季节变化*

Tab. 1 Seasonal variations of environmental factors and Chl. a in river network of Chongming Island and Yangtze River

\begin{tabular}{|c|c|c|c|c|c|c|c|c|c|c|c|c|}
\hline & $\begin{array}{l}\text { 水温/ } \\
{ }^{\circ} \mathrm{C}\end{array}$ & $\mathrm{pH}$ & $\begin{array}{c}\mathrm{DO} / \\
(\mathrm{mg} / \mathrm{L})\end{array}$ & $\begin{array}{l}\text { 电导率/ } \\
(\mu \mathrm{S} / \mathrm{cm})\end{array}$ & $\begin{array}{l}\text { 浊度/ } \\
\text { NTU }\end{array}$ & $\begin{array}{l}\text { Chl. a/ } \\
(\mu \mathrm{g} / \mathrm{L})\end{array}$ & $\begin{array}{c}\mathrm{TN} / \\
(\mathrm{mg} / \mathrm{L})\end{array}$ & $\begin{array}{c}\mathrm{TP} / \\
(\mathrm{mg} / \mathrm{L})\end{array}$ & $\begin{array}{l}\mathrm{NH}_{3}-\mathrm{N} / \\
(\mathrm{mg} / \mathrm{L})\end{array}$ & $\begin{array}{l}\mathrm{NO}_{3}^{-}-\mathrm{N} / \\
(\mathrm{mg} / \mathrm{L})\end{array}$ & $\begin{array}{l}\mathrm{SiO}_{3}-\mathrm{Si} / \\
(\mathrm{mg} / \mathrm{L})\end{array}$ & $\begin{array}{c}\text { DOC/ } \\
(\mathrm{mg} / \mathrm{L})\end{array}$ \\
\hline \multirow[t]{4}{*}{ 崇明河网 } & $\begin{array}{c}6.6 \\
(1.41)\end{array}$ & $\begin{array}{c}7.97 \\
(0.10)\end{array}$ & $\begin{array}{c}9.98 \\
(0.79)\end{array}$ & $\begin{array}{c}840 \\
(269)\end{array}$ & $\begin{array}{c}44.6 \\
(20.8)\end{array}$ & $\begin{array}{c}8.06 \\
(6.08)\end{array}$ & $\begin{array}{c}4.99 \\
(1.01)\end{array}$ & $\begin{array}{c}0.19 \\
(0.02)\end{array}$ & $\begin{array}{c}1.61 \\
(0.22)\end{array}$ & $\begin{array}{c}3.31 \\
(0.76)\end{array}$ & $\begin{array}{c}6.70 \\
(0.68)\end{array}$ & $\begin{array}{c}6.83 \\
(1.30)\end{array}$ \\
\hline & $\begin{array}{c}12.0 \\
(1.37)\end{array}$ & $\begin{array}{c}7.98 \\
(0.12)\end{array}$ & $\begin{array}{c}9.67 \\
(0.82)\end{array}$ & $\begin{array}{c}701 \\
(276)\end{array}$ & $\begin{array}{c}43.7 \\
(21.0)\end{array}$ & $\begin{array}{c}21.76 \\
(15.52)\end{array}$ & $\begin{array}{c}4.07 \\
(1.10)\end{array}$ & $\begin{array}{c}0.14 \\
(0.04)\end{array}$ & $\begin{array}{c}0.64 \\
(0.37)\end{array}$ & $\begin{array}{c}3.08 \\
(0.79)\end{array}$ & $\begin{array}{c}5.47 \\
(0.69)\end{array}$ & $\begin{array}{c}4.92 \\
(1.67)\end{array}$ \\
\hline & $\begin{array}{c}29.8 \\
(1.04)\end{array}$ & $\begin{array}{c}7.93 \\
(0.26)\end{array}$ & $\begin{array}{c}7.39 \\
(2.06)\end{array}$ & $\begin{array}{c}386 \\
(91)\end{array}$ & $\begin{array}{c}43.1 \\
(15.7)\end{array}$ & $\begin{array}{c}27.82 \\
(11.27)\end{array}$ & $\begin{array}{c}4.04 \\
(0.47)\end{array}$ & $\begin{array}{c}0.23 \\
(0.05)\end{array}$ & $\begin{array}{c}0.43 \\
(0.18)\end{array}$ & $\begin{array}{c}3.20 \\
(0.35)\end{array}$ & $\begin{array}{c}8.63 \\
(1.32)\end{array}$ & $\begin{array}{c}5.74 \\
(2.04)\end{array}$ \\
\hline & $\begin{array}{c}22.0 \\
(1.23)\end{array}$ & $\begin{array}{c}7.88 \\
(0.24)\end{array}$ & $\begin{array}{c}6.10 \\
(1.43)\end{array}$ & $\begin{array}{l}330 \\
(59)\end{array}$ & $\begin{array}{c}57.0 \\
(15.5)\end{array}$ & $\begin{array}{c}14.70 \\
(8.77)\end{array}$ & $\begin{array}{c}2.33 \\
(0.26)\end{array}$ & $\begin{array}{c}0.15 \\
(0.05)\end{array}$ & $\begin{array}{c}0.15 \\
(0.11)\end{array}$ & $\begin{array}{c}1.90 \\
(0.11)\end{array}$ & $\begin{array}{c}7.53 \\
(0.52)\end{array}$ & $\begin{array}{c}3.12 \\
(0.77)\end{array}$ \\
\hline \multirow[t]{4}{*}{ 长江引水 } & 8.7 & 7.97 & 10.93 & 473 & 64.0 & 3.03 & 3.36 & 0.21 & 1.19 & 2.04 & 6.52 & 4.09 \\
\hline & 10.2 & 8.11 & 10.67 & 305 & 48.8 & 2.62 & 2.34 & 0.10 & 0.35 & 1.94 & 6.14 & 2.54 \\
\hline & 28.9 & 7.94 & 6.76 & 292 & 55.6 & 6.13 & 3.46 & 0.13 & 0.34 & 3.01 & 8.19 & 3.82 \\
\hline & 21.3 & 7.73 & 5.40 & 289 & 63.8 & 3.74 & 2.15 & 0.09 & 0.04 & 1.91 & 7.26 & 2.34 \\
\hline
\end{tabular}

*括号内数据为标准差.

崇明河网内营养盐水平较高, 氮污染问题尤为严重. 氮、磷营养盐含量已远远超过公认富营养化发生所 需要的國值 ${ }^{[9]}$. 其中 $\mathrm{TN}$ 全年为地表水劣 $\mathrm{V}$ 类标准, $\mathrm{TP}$ 为 III $\sim \mathrm{IV}$ 类水质标准. $\mathrm{NH}_{3}-\mathrm{N}$ 全年差异较大, 夏、秋季 基本为 $\mathrm{I} \sim$ II 类标准; 而冬、春季为 III $\sim \mathrm{V}$ 类水质标准. 全年河网中 $\mathrm{TN} 、 \mathrm{TP} 、 \mathrm{NH}_{3}-\mathrm{N} 、 \mathrm{NO}_{3}^{-}-\mathrm{N} 、 \mathrm{SiO}_{3}-\mathrm{Si}$ 和 $\mathrm{DOC}$ 含量均值分别比长江引水提高了 $36.89 \% 、 43.52 \% 、 104.91 \% 、 31.70 \% 、 0.24 \%$ 和 $61.07 \%$, 表明岛内营养物 质的输人造成岛内河道中的氮、磷和有机物质的含量明显增加. 与营养盐相比, Chl. a 含量的升高则更为显 著. 冬季、春季、夏季和秋季河网中的 Chl. a 含量比长江引水分别增加了 $166.01 \% 、 730.53 \% 、 353.83 \%$ 和 $293.05 \%$. 这说明与长江口水环境相比, 岛内河网环境更利于促进藻类初级生产力的提高. 根据 OECD 富营 养化单因子评价标准 ${ }^{[10]}, \mathrm{Chl}$. a 含量超过 $11 \mu \mathrm{g} / \mathrm{L}$ 被看作水体发生富营养化的标志. 除冬季外, 河网内其他 季节中的 Chl. a 含量均值都达到了富营养水平.

\section{2 营养状态的季节变化特征}

冬季、春季、夏季和秋季崇明岛河网的营养状态指数 $\left(T S I_{\mathrm{M}}\right)$ 均值分别为 $61.12 、 65.15 、 67.90$ 和 62.85 , 高于长江引水的均值 57.10、59.67、52.72 和 55.20 (图 2). 可以看出, 长江引水被引人岛内河网后, 营养状态出 现了明显的提升. 根据营养状态指数的评价标准, $53 \leqslant T S I_{\mathrm{M}}<65$ 为富营养状态, $T S I_{\mathrm{M}} \geqslant 65$ 为重富营养状态 ${ }^{[11]}$. 全年 崇明岛河网的营养状态均达到了富营养状态,其中春季和夏季达到重富营养状态.

\section{3 藻类群落对 Chl. a 的贡献}

崇明岛河网与长江引水中冬季、春季和秋季硅藻对 Chl. a 的贡献高于蓝藻和绿藻; 而夏季蓝藻和绿藻的 
Chl. a 比例高于硅藻. 与长江引水相比, 岛内河网水体主要 表现为硅藻贡献比例的下降,冬季、春季、夏季和秋季的硅 藻贡献比例分别比长江引水降低了 $8.66 \% 、 14.00 \%$ 、 $9.42 \%$ 和 $6.52 \%$. 在营养状态和 Chl. a 含量较高的春季和 夏季, 硅藻的贡献比例下降程度略高于秋季和冬季 (图 3). 硅藻的 Chl. a 贡献比例与 Chl. a 含量和营养状态均呈显著 负相关 $(P<0.01)$, 表明岛内河网环境中 Chl. a 含量的增加 以及营养状态的提高过程中, 伴随着硅藻贡献比例的下降 以及蓝藻和绿藻贡献比例的上升 (图 4). 因此通过对硅藻 群落 Chl. a 的贡献变化进行追踪, 可以较准确地掌握岛内 初级生产力和营养状态的动态变化.

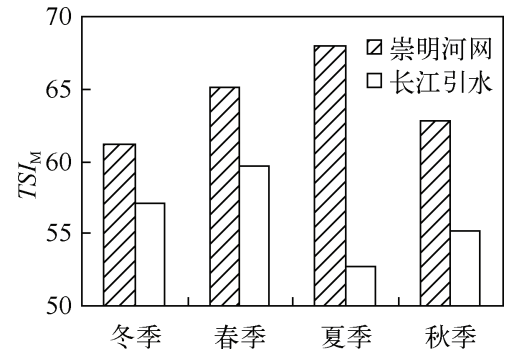

图 2 崇明岛河网与长江引水

营养状态的季节变化

Fig. 2 Seasonal variations of trophic state in river network of Chongming Island and Yangtze River
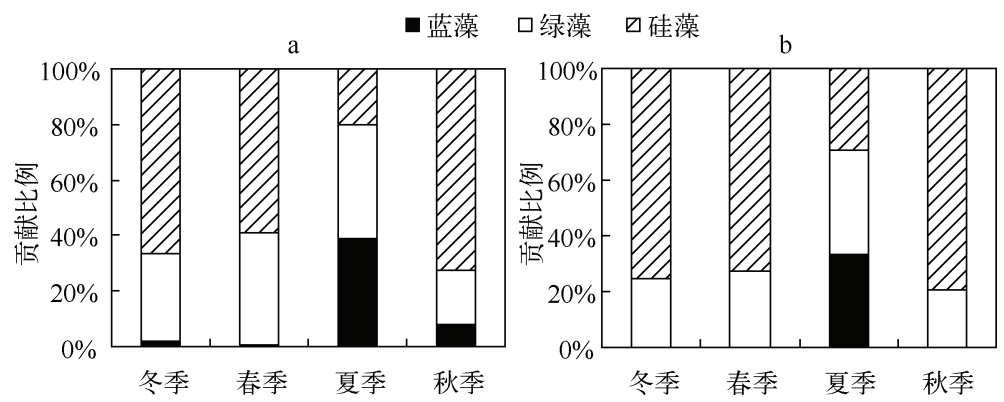

图 3 崇明岛河网 (a) 与长江引水 (b) 中藻类群落对 Chl. a 的贡献情况

Fig. 3 Contribution of algal community in Chl. a in river network of Chongming Island(a) and Yangtze River(b)

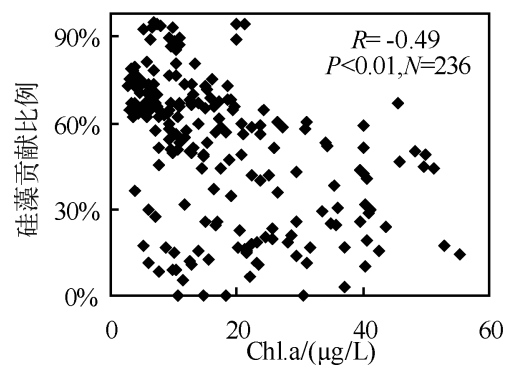

$\mathrm{b}$

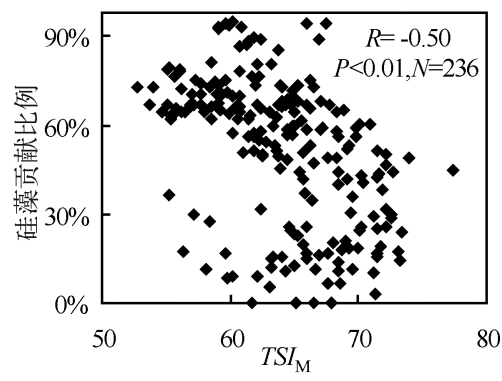

图 4 硅藻群落对 Chl. a 的贡献比例与 Chl. a 浓度 (a) 和营养状态指数 (b) 的相关关系

Fig. 4 Correlation between proportion of diatom to Chl. a and Chl. a concentration(a), $\operatorname{TSI}_{\mathrm{M}}(\mathrm{b})$

\section{4 藻类与环境因子的关系}

崇明岛河网水环境理化因子中水温、 $\mathrm{pH}$ 与 Chl. a 含量呈显著正相关 $(P<0.01)$, 而浊度与 Chl. a 含量呈 显著负相关 $(P<0.01)$; 营养盐因子中 $\mathrm{TN} 、 \mathrm{TP} 、 \mathrm{NO}_{3}^{-}-\mathrm{N} 、 \mathrm{DOC}$ 均与 Chl. a 含量呈显著正相关 $(P<0.01)($ 表 2 ). 水温的变化会不同程度地影响藻类的新陈代谢. 在适宜的温度范围内, 水温的升高能够促进藻类的生

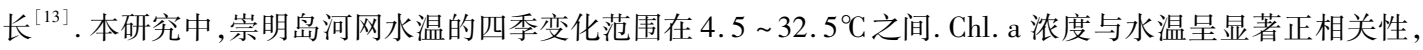
表明水温在该范围内的升高能够明显促进崇明岛河网藻类的生长. 天然水体中, 藻类的快速增长使其光合 作用加强, 能够引起 $\mathrm{pH}$ 和 $\mathrm{DO}$ 的升高 ${ }^{[14]}$. 河网中 Chl. a 浓度与 $\mathrm{pH}$ 间的显著正相关证明了藻类的生长是引 起 $\mathrm{pH}$ 升高的主导因素之一. 与 $\mathrm{pH}$ 不同, Chl. a 浓度与 DO 间不存在显著相关性 $(P>0.05)$, 说明藻类活动 并不是引起 DO 变化的主导因素. DO 在冬、春季节含量较高, 主要与低温条件下 DO 的溶解度升高有关. 水 温与 DO 之间的显著负相关性 $(P<0.01)$ 也证明了崇明岛河网 DO 变化主要受水温变化的影响. 浊度与 
Chl. a 浓度呈显著负相关则说明了长江引水进人河网后, 泥沙悬浮物的沉降和水体透明度升高是显著促进 藻类生长的重要因素之一.

营养盐中 TN、TP 与 Chl. a 含量均存在显著正相关, 说明氮、磷营养盐的增加促进了崇明岛河道藻类的 生长. TP 与 Chl. $\mathrm{a}$ 的相关系数要明显高于 TN. Redfield 比例 (氮、磷原子比为 16) 被认为是藻类健康生长和 生理平衡所需的营养元素比例. 中国海岸河口的氮磷原子比范围为 30:1 80:1, 可利用氮源远高于磷源导致 了河口水体中藻类生长的磷限制超过氮限制 ${ }^{[15]}$. 崇明岛河道氮污染较为严重, 全年氮磷原子比均值高达 48.95, 因此较高的氮磷原子比可能是导致 TP 对藻类生长的促进作用大于 TN 的主要原因. 尽管 TN 与 Chl. a 之间存在显著相关性, 但 $\mathrm{NO}_{3}^{-}-\mathrm{N}$ 和 $\mathrm{NH}_{3}-\mathrm{N}$ 与 Chl. a 的关系并不相同. $\mathrm{NO}_{3}^{-}-\mathrm{N}$ 与 Chl. a 之间存在显著正相 关, 而 $\mathrm{NH}_{3}-\mathrm{N}$ 与 Chl. a 之间的相关性不显著 $(P>0.05)$. 研究表明, 藻类一般会优先利用水体中的 $\mathrm{NH}_{3}-\mathrm{N}$, 因为 $\mathrm{NH}_{3}-\mathrm{N}$ 在被同化时不需要降解, 而 $\mathrm{NO}_{3}^{-}-\mathrm{N}$ 需要被还原才能利用 ${ }^{[16]}$. 但也有研究认为, 藻类对氮源的利用具 有选择性, 并且与藻类的种类、营养状态以及水环境中 $\mathrm{NO}_{3}^{-}-\mathrm{N}$ 和 $\mathrm{NH}_{3}-\mathrm{N}$ 的相对浓度均有关系. 李哲等 ${ }^{[17]}$ 在 研究三峡回水区藻类季节变化时指出藻类生长对 $\mathrm{NO}_{3}^{-}-\mathrm{N}$ 的吸收利用较 $\mathrm{NH}_{3}-\mathrm{N}$ 更明显. 本研究的结果也证 明当 $\mathrm{NH}_{3}-\mathrm{N}$ 存在且含量较充足时, $\mathrm{NO}_{3}^{-}-\mathrm{N}$ 仍可作为藻类生长的重要氮源. 崇明岛河道中 $\mathrm{NO}_{3}^{-}-\mathrm{N}$ 浓度较高, 监测期间均值为 $2.87 \mathrm{mg} / \mathrm{L}$, 因此充足的 $\mathrm{NO}_{3}^{-}-\mathrm{N}$ 含量能够保证藻类生长对氮源的需求. 除了氮、磷营养盐, DOC 也与 Chl. a 含量存在显著正相关. 一方面, 大量的营养盐和有机物从外界环境进人到水体能够刺激藻 类的生长 ${ }^{[18]}$. 另一方面, 藻类在生长和死亡过程中都会向水体释放有机物而导致有机物浓度的升高 ${ }^{[19]}$. 因 此崇明岛河网中 DOC 与 Chl. a 间的显著相关性应是二者相互作用的结果.

表 2 崇明岛河网中 Chl. a 与环境因子的相关关系

Tab. 2 Relationships between Chl. a and environmental factors in river network of Chongming Island

\begin{tabular}{|c|c|c|c|c|c|c|c|c|c|c|c|}
\hline & 水温 & $\mathrm{pH}$ & DO & 浊度 & 电导率 & Chl. a & $\mathrm{TN}$ & TP & $\mathrm{NH}_{3}-\mathrm{N}$ & $\mathrm{NO}_{3}^{-}-\mathrm{N}$ & $\mathrm{SiO}_{3}-\mathrm{Si}$ \\
\hline $\mathrm{pH}$ & $-0.16^{*}$ & 1 & & & & & & & & & \\
\hline DO & $-0.73^{* *}$ & $0.65^{* *}$ & 1 & & & & & & & & \\
\hline 浊度 & $0.18^{* *}$ & $-0.24^{* *}$ & $-0.27^{* *}$ & 1 & & & & & & & \\
\hline 电导率 & $-0.75^{* *}$ & 0.13 & $0.49^{* *}$ & $-0.35^{* *}$ & 1 & & & & & & \\
\hline Chl. a & $0.26^{* *}$ & $0.22^{* *}$ & 0.01 & $-0.37^{* *}$ & -0.03 & 1 & & & & & \\
\hline $\mathrm{TN}$ & $-0.51^{* *}$ & $0.17^{*}$ & $0.36^{* *}$ & $-0.44^{* *}$ & $0.69^{* *}$ & $0.20^{\text {** }}$ & 1 & & & & \\
\hline $\mathrm{TP}$ & 0.10 & 0.08 & 0.02 & -0.19 & 0.14 & $0.44^{* *}$ & $0.41^{* *}$ & 1 & & & \\
\hline $\mathrm{NH}_{3}-\mathrm{N}$ & $-0.68^{* *}$ & 0.06 & $0.42 * *$ & $-0.29^{* * *}$ & $0.73^{\text {** }}$ & -0.07 & $0.80^{* *}$ & $0.31 * *$ & 1 & & \\
\hline $\mathrm{NO}_{3}^{-}-\mathrm{N}$ & $-0.33^{* *}$ & $0.15^{*}$ & $0.22^{* *}$ & $-0.37^{* * *}$ & $0.52^{* *}$ & $0.18^{* *}$ & $0.91^{* *}$ & $0.32 * *$ & $0.51^{* *}$ & 1 & \\
\hline $\mathrm{SiO}_{3}-\mathrm{Si}$ & $0.42 * *$ & -0.07 & $-0.36^{* *}$ & 0.08 & $-0.28^{* *}$ & 0.09 & -0.09 & 0.40 ** & -0.15 & -0.02 & 1 \\
\hline DOC & $-0.30^{* *}$ & 0.06 & $0.20^{* *}$ & $-0.36^{* *}$ & $0.48^{* *}$ & $0.36^{* *}$ & $0.71^{* *}$ & $0.55^{* *}$ & $0.64^{* *}$ & $0.56^{* *}$ & $0.13^{*}$ \\
\hline
\end{tabular}

** 表示在 0.01 水平上呈显著相关 (双尾检验),$N=236 ; *$ 表示在 0.05 水平上呈显著相关 (双尾检验) , $N=236$.

藻类群落与环境因子的 RDA 分析结果见表 3 和图 5. 表 3 列出了 RDA 分析的统计信息,其中轴 1 和轴 2 共解释了 $96 \%$ 藻类与环境因子相关性的信息. 在藻类种群与环境因子间的相关程度中, 轴 1 藻类与环境因 子的相关性高达 0.902 , 轴 2 为 0.806 . 这说明通过轴 1 和轴 2 就能够较好地反映出浮游植物和环境因子之 间的关系.

表 3 崇明岛河网藻类群落与环境因子的 $\mathrm{RDA}$ 统计结果

Tab. 3 RDA results of algal community and environmental factors in river network of Chongming Island

\begin{tabular}{lccccc}
\hline 参数 & 轴 1 & 轴 2 & 轴 3 & 轴 4 & 总方差 \\
\hline 特征值 & 0.525 & 0.152 & 0.027 & 0.168 & 1.000 \\
藻类与环境因子相关关系 & 0.902 & 0.806 & 0.432 & 0.000 & \\
藻类种类累积百分数 $/ \%$ & 52.5 & 67.7 & 70.4 & 87.2 & \\
藻类与环境因子相关性累积百分数 $/ \%$ & 73.8 & 96.0 & 100 & 100 & \\
\hline
\end{tabular}


图 5 为藻类群落与环境因子之间的 RDA 排序. 在由轴 1 和轴 2 构成的平面中, 与蓝藻变化相一致的环 境因子是水温、 $\mathrm{TP} 、 \mathrm{Chl} . \mathrm{a}$ 和 $\mathrm{SiO}_{3}-\mathrm{Si}$; 与绿藻呈明显正相关的环境因子是 $\mathrm{TN} \mathrm{NO}_{3}^{-}-\mathrm{N}$; 与硅藻变化趋势一致的环 境因子是浊度. 蓝藻中绝大多数藻种均带有异形胞, 能够固定大气中的游离态氮 ${ }^{[20]}$. 异形胞的存在使天然水 体中蓝藻对氮的需求低于磷. 当外界磷源充足时, 蓝藻比其他藻类更具有竞争优势. 此外, 蓝藻比较偏好水 温较高的环境, 夏季频发的蓝藻暴发事件已经被证明与蓝藻在高温下具有相对较高的生长速率有关 ${ }^{[21]}$. 因 此崇明岛河网中蓝藻的增加主要与水温和 $\mathrm{TP}$ 含量的升高有关. 尽管 $\mathrm{SiO}_{3}-\mathrm{Si}$ 与蓝藻也存在较好的正相关关 系, 但这种关系主要是由于 $\mathrm{SiO}_{3}-\mathrm{Si}$ 含量最高的夏季同样也是蓝藻生长最旺盛的季节. 本研究认为 $\mathrm{SiO}_{3}-\mathrm{Si}_{\text {的 }}$ 变化并不能直接影响蓝藻的生长. 绿藻与 $\mathrm{TN} 、 \mathrm{NO}_{3}^{-}-\mathrm{N}$ 的正相关关系最为显著. 当水体中的氮、磷质量比高达 $20 \sim 50$ 时, 绿藻具有明显的生长优势 ${ }^{[22]}$. 本研究中, 在崇明岛河网氮磷质量比较高且均值为 22.11 的情况 下, TN 的增加仍然能够显著促进崇明岛内河道中绿藻的生长. 绿藻与 $\mathrm{NO}_{3}^{-}-\mathrm{N}$ 的密切关系则说明了 $\mathrm{NO}_{3}^{-}-\mathrm{N}$ 是内河中绿藻最重要的氮源利用方式. 与蓝藻和绿藻不同, 岛内河道中硅藻的变化只与浊度存在明显的正 相关, 营养盐并不是硅藻生长的促进因子. 硅藻由于其个体比重较大, 需要较强的水动力增加浮力来对抗沉 降, 从而提高其光合作用强度. 硅藻还能够忍受水体混合产生的切力、搅动 ${ }^{[23]}$. 但浊度与其他藻种间的响应 程度并不一致. 绿藻与浊度之间存在明显的负相关, 说明较高的浊度引起水体透明度的降低对绿藻的生长 起到了限制作用. 而蓝藻与浊度间较差的相关性则说明了蓝藻受浊度变化的影响很小. 由于蓝藻细胞内一 般都含有伪空胞, 因此光照度对蓝藻垂直迁移的影响不同于其他藻类. 伪空胞的存在能够使蓝藻通过调节 自身浮力使其处于水体中有利的位置, 以适应生长的需要, 从而降低了浊度对蓝藻的影响 ${ }^{[16]}$. 此外, 蓝藻中 特有的藻胆蛋白扩展了其光合作用的波长, 也使得蓝藻在高浊度条件下具有比其它藻类更宽的光吸收 波段 ${ }^{[20]}$.

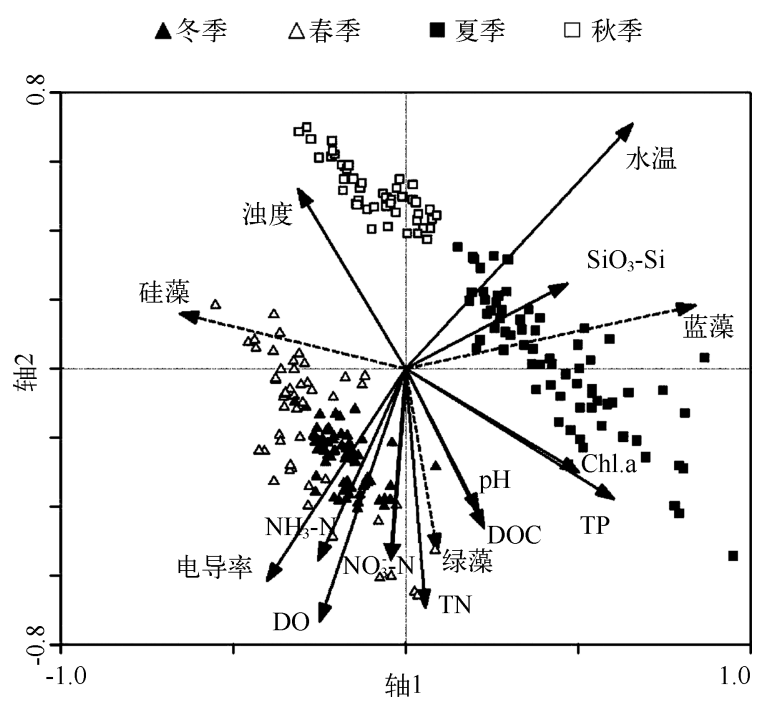

图 5 崇明岛河网藻类群落与环境因子的 RDA 排序

Fig. 5 RDA ordination of algal community and environmental factors in river network of Chongming Island

从藻种间的关系来看, 蓝、绿藻与硅藻间存在明显负相关. Chl. a 和蓝、绿藻存在正相关, 与硅藻存在负 相关. 这说明蓝藻和绿藻是岛内河道 Chl. a 增加过程中的主要贡献者; 而当 Chl. a 含量较低时, 硅藻往往占 有较大的优势. 从各季节监测点位在排序图中的分布来看,轴 2 对夏季和其他季节有着较好的分割, 夏季藻 类群落特征与其他季节存在明显差异. 夏季监测点位与蓝藻和 Chl. a 代表向量的关系较其他季节更为密切, 较高的藻类生物量和蓝藻的群落优势是造成夏季与其他季节间存在差异的主要原因. 


\section{3 参考文献}

[ 1 ] 吴庆龙, 谢 平, 杨柳燕等. 湖泊蓝藻水华生态灾害形成机理及防治的基础研究. 地球科学进展, 2008,23(11): 1115-1122.

[2 ] 胡 韧. 珠海水库富营养化现状、浮游植物群落特征与蓝藻水华风险分析 [学位论文]. 广州: 暨南大学,2009.

[3] 杨东方, 陈生涛, 胡 均等. 光照、水温和营养盐对浮游植物生长重要影响大小的顺序. 海洋环境科学, 2007,26 (3) :201-207.

[4] 吴晓辉,李其军. 水动力条件对藻类影响的研究进展. 生态环境学报,2010,19(7):1732-1738.

[ 5 ] 应荣弟,徐 华. 崇明岛水系改造对水资源的影响初探. 上海建设科技,2005,4:10-12.

[6 ] Yin HL. Simulation of non-point pollutants evolution in coastal plain island-a case study of Chongming Island. Journal of Hydrodynamics, 2008, 20(2) : 246-253.

[ 7 ] 陈宇炜, 陈开宁, 胡耀辉. 浮游植物叶绿素 a 测定的 “热乙醇法” 及其测定误差的探讨. 湖泊科学, 2006, 18 (5): $550-552$.

[ 8 ] Ter Braak CJ, Prentice IC. A theory of gradient analysis. Advances in Ecological Research, 1988, (8) : 271-317.

[ 9 ] 金相灿,刘树坤,章宗涉等. 中国湖泊环境:第 1 册. 北京:海洋出版社, 1995.

[10] OECD. Eutrophication of waters: Moniotring assessment and conrtol. Paris: OECD Publication, 1982.

[11] 蔡庆华. 湖泊富营养化评价方法综述. 湖泊科学, 1997,9(1):89-94.

[12 ] Sommer U, Gliwicz ZM, Lampert W et al. The PEG-model of seasonal suecession of planktonic events in fresh waters. Archives of Hydrobiology, 1986, 106(4) : 433-471.

[13] 金相灿, 储昭升,杨 波等. 温度对水华微囊藻及孟氏浮游蓝丝藻生长、光合作用及浮力变化的影响. 环境科学学 报,2008,28(1):50-55.

[14] 刘佳佳. 河口边滩湖泊营养盐及藻类生长动力学研究——以崇明北湖为例 [学位论文]. 上海: 同济大学, 2008 .

[15] Jiao NZ, Wang R. Size structures of microplankton biomass and production in Jiaozhou Bay. Journal of Plankton Research, 1994, 16(12) : 1609-1625.

[16] 蒋汉明,高坤山.氮源及其浓度对三角褐指藻生长和脂肪酸组成的影响. 水生生物学报,2004,28(5):545-551.

[17］李 哲, 郭劲松,方 芳等. 三峡小江回水区蓝藻季节变化及其与主要环境因素的相互关系. 环境科学, 2010,31 (2) :301-309.

[18 ] Pace ML, Cole JJ, Carpenter SR et al. Whole-lake carbon-13 additions reveal terrestrial support of aquatic food webs. Nature, 2004, 427 : 240-243.

[19] 叶 麟. 三峡水库香溪河库湾富营养化及春季水华研究 [学位论文]. 北京: 中国科学院大学,2010.

[20］马祖友.蓝藻的生长生理特征及其竞争优势研究 [学位论文].杨凌:西北农林科技大学,2005.

[21] 孔繁翔,高 光. 大型浅水富营养化湖泊中蓝藻水华形成机理的思考.生态学报,2005,25(3) :589-595.

[22] Bulgakov NG, Levich AP. The nitrogen: phosphorus ratio as a factor regulating phytoplankton community structure. Archiv fiir Hydrobiologie, 1999, 146(1) : 3-22.

[23] 杨东方, 于子江, 张 柯等. 营养盐硅在全球海域中限制浮游植物的生长. 海洋环境科学, 2008, 27 (5):547-553. 